\title{
Preparing for a News Interview ${ }^{1}$
}

\author{
Ricky Telg and Lisa Lundy²
}

A newspaper reporter has just called you to schedule a mid-afternoon interview for the tomorrow's newspaper. What do you do? Well, the information that follows will help you decide what to do and give you tips on how to do it. This fact sheet discusses strategies to help you succeed in presenting yourself in an interview for television, radio or print.

Many people assume that being interviewed is as simple as walking into an office or studio and waiting for a reporter or interviewer to ask questions. However, if you are not fully prepared, both in terms of the content of your presentation and the process - what to expect during an interview-being interviewed can be a frightening experience. Conversely, if you know your material and feel confident about your ability and appearance, an interview can be a rewarding and enjoyable endeavor.

\section{General Interview Guidelines}

The following recommendations are general hints that will give you the tools you need to succeed in most interviews. Going through these steps in a mock news interview setting will help you prepare for the "real thing." (A mock news interview is when someone acts as a reporter and asks you questions that a "real" reporter would ask. You may wish to video record the mock interview so you can review and critique your performance.) The interview skills described in this section pertain to all forms of media unless otherwise noted at the end of the sentence.

\section{Preparation}

- Prepare two to three ideas you want to convey. These are your communication points, the three most important issues or points you hope to address and get across to the reporter during the interview.

- Make alist of the questions you anticipate being asked. What is the story about? What is the reporter looking for? Anticipate issues and questions that may arise during the interview and be prepared to use those issues to launch your communication points.

- Know your subject matter well.

- Have your best answers ready.

\section{Simplicity}

- Make short, simple, and specific statements.

- Explain your most important point first.

- Don't stray from the topic.

- Summarize and then elaborate. (Example: "We have the best organization in the area because our volunteers really care. Let me explain what I mean...")

\section{Answering Questions}

- Pause after complete statements. The interviewer will appreciate these breaks during the editing process (radio and TV).

- When you think you've answered a question adequately, don't feel compelled to keep talking simply because the

1. This document is AEC338, one of a series of the Department of Agricultural Education and Communication, UF/IFAS Extension. Original publication date April 2000. Revised May 2021. Visit the EDIS website at https://edis.ifas.ufl.edu for the currently supported version of this publication.

2. Ricky Telg, professor; and Lisa Lundy, professor, Department of Agricultural Education and Communication, UF/IFAS Extension, Gainesville, FL 32611.

The Institute of Food and Agricultural Sciences (IFAS) is an Equal Opportunity Institution authorized to provide research, educational information and other services

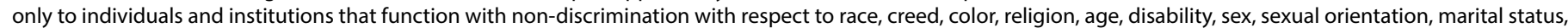

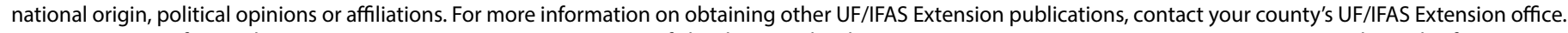
U.S. Department of Agriculture, UF/IFAS Extension Service, University of Florida, IFAS, Florida A \& M University Cooperative Extension Program, and Boards of County Commissioners Cooperating. Nick T. Place, dean for UF/IFAS Extension. 
interviewer has a microphone up to your mouth. If you're satisfied with your answer, sit in silence. Rambling leads you to say the wrong thing.

- Do not say the reporter's name in the middle of a sentence; do not use phrases like "as I explained earlier." Example: "We got all of our information in March 1995, John, and as I explained earlier, this will back up our first estimates." The reporter's name and the phrase will be difficult to edit. Also, viewers may not know what you and the reporter have discussed previously, and they may not understand what you are referring to (radio and TV).

- Think before you speak. Avoid fillers such as $u h$, ah, well, yeah, and you know (radio and TV). It's okay to pause and take your time.

- Respond to negative questions with positive responses.

- Always tell the truth. Your credibility is crucial.

- Avoid "off the record." If you say something to a report, expect that it will end up in print. If you don't want it printed, don't say it.

- Avoid "no comment" answers. It sounds as if you have something to hide. It is okay, however, to tell a reporter you'll need to research a question and follow up later.

\section{Try these yourself...}

Determine your communication points. What three ideas do you want to get across to the reporter?

List some possible questions a reporter might ask. Be sure to prepare answers to these questions.

Ask a friend to interview you and record the mock news interview. Analyze it for strengths in your presentation and areas you need to improve.

\section{The Games Interviewers Play}

Some interviewers can become hostile; others are just uninformed. Don't get caught in an emotional or intellectual game with the interviewer. Following are some "interviewer types" and question traps and some responses you may want to try.

\section{Interviewer "Types"}

Machine Gunner. Asks so many questions, you don't know which one to answer first.

Verbal Bridge: "Well, Bob, you've asked several interesting questions. First, I'd like to address..."

Interrupter. Jumps in before you've had a chance to complete your response.

Verbal Bridge: Let him complete the interruption, then say:
"Before I answer that, I'd like to complete my thought."

Paraphraser. Tries to put words in your mouth; e.g., "Do you mean to sit there and tell me there's no problem with..."

Verbal Bridge: "No, Sarah, that isn't what I said. What I said was..." and repeat your point.

Unprepared Interviewer. May have vague questions or require you to provide a lot of background before you can get to your key message.

Verbal Bridge: Take the opportunity to steer the interview in the direction you want to go. Rephrase the question to make it more specific. "By your question, I think you're referring to...let me put that in perspective."

\section{Strategies for Handling "Question Traps"}

Either/Or. When the answer is not "black or white," say so.

Absent Party. Don't get trapped into being a spokesperson for another individual, business or organization or into criticizing an absent person or organization. Don't speculate outside your area of expertise.

False Statement. Correct incorrect information immediately. Don't repeat the misinformation; this only reinforces it.

Hypothetical. You do not have to answer a question that is hypothetical or conditional. It presents a scenario that never occurred.

\section{Let's Talk}

For any recorded interview (radio or television), the impact of your spoken message depends on how you say it. The sound of your voice determines how well you hold the audience's attention.

The ability to speak well can be cultivated through practice. Common voice problems involve pitch, rate and articulation. The habit of inflecting up at the ends of sentences and phrases is a pitch problem. Making everything you say sound like a question undermines your authority. You will sound more assertive if you lower your pitch and inflect downward.

Do you talk too fast or too slow? The speed with which you talk is your speaking rate. While sprinting through your message may leave listeners behind, talking too slowly may 
bore them. How do you work on slowing down or speeding up your speech? Here are a few tips: Record yourself talking with someone, preferably in a "mock news interview" situation. Play it back and listen to how fast or slow you speak. Practice establishing a rate that is easy for people to understand. Once you've established a good pitch and rate, practice varying them, along with your volume, to add emphasis and expression to your message. Without variety, your voice becomes boring.

You will make a better impression on your audience if you articulate. Thisdoesn't mean getting rid of your accent-if you have one. The key to improvement is tuning your ear to your voice attributes. When you recognize them, you'll be able to work at making the best of your own natural abilities while articulating clearly.

\section{Try this yourself...}

Analyze your mock news interview recording for pitch, rate and articulation. Do you vary your pitch? Do you speak too fast or too slow? Do you speak distinctly?

\section{Appearance is Everything}

Television viewers will judge your trustworthiness by your substance and your style. However, your appearance also must match viewer expectations.

\section{Clothing (in a studio setting)}

- Stick to a conservative, "professional appearance" style.

- Wear a tailored sports coat or appropriate professional dress for your context.

- Skirt length should be appropriate-no mini-skirts.

\section{Clothing (in an "on-location" setting)}

- Dress in "natural" clothes. You are not expected to wear a suit if you're being interviewed in a peanut field or a citrus grove.

- Avoid hats. If you must wear one, push back the brim so people can see your eyes.

\section{Jewelry}

- Wear only a few pieces.

- Avoid "clunky" or dangling jewelry. Big gold or high-gloss pieces can reflect studio lights.

- Short necklaces are best. Long necklaces rub against clip-on microphones.

\section{Make-Up}

- Aim for a "natural" look.

- Use a matte finish to reduce shine (this includes lipstick).

- Be sure your nails are manicured.

- Most likely, you will not have to add make-up at the interview but be open to the suggestion. Some television stations will ask that you apply make-up because of the bright studio lights.

\section{Enthusiasm}

- Be animated. Use natural gestures, facial expressions, and body language to add vitality to your words. However, be careful not to overdo it.

- Smile. A good first impression can help establish your credibility.

- Be conversational.

- Say it in 30 seconds or less.

- Deliver your message with confidence. After all, you know more about the story topic than the interviewer.

\section{Body Language}

- Look at the interviewer, not the camera. Glances up or to the side make you appear shifty-eyed and untrustworthy.

- Sit still in your chair. Rocking or swiveling can take you out of a cameraperson's shot.

- Don't look at notes during an interview, although you can refer to them if you get "stuck."

- Stay seated when the interview is over. You might still be on camera and trip over a wire or do something else awkward.

\section{Other Warnings}

- Don't chew gum or play with your pocket change or keys while on the air.

- Never wear black or white for television interviews. Aim for midtone colors. Dark- or bright-colored clothes can make your face look extremely washed out or dark under television studio lighting.

- Your blouse/shirt should have a place to clip a microphone.

- Don't wear light-sensitive glasses. Studio lighting will make your glasses darker; viewers won't be able to see your eyes. 


\section{Nerves of Steel}

You are now ready for radio and television interviews. You are prepared, you look great, and you are ready to go. You arrive at the station on time, and then "IT" happens. You realize YOU will be the one in front of the microphone or camera. Your palms sweat. Your stomach churns. What are you going to do?

Stage fright is not a fatal disease. Just remember that we never look as nervous as we feel. With a few tips, you can overcome your fears and give a successful interview.

- Be organized and concise. Read over your material in advance to keep from sounding strained and awkward.

- Concentrate on the question you're being asked. Pause before answering a question just long enough to formulate an outline of the answer.

- Before the interview starts, take a deep breath, get a drink of water, laugh or yawn. (Why yawn? Because you can't yawn and be tense at the same time. Even a nervous laugh to yourself will help relieve tension.) Each individual must find his or her own way to deal with nervousness.

- Remind yourself that you were asked to be interviewed because you're knowledgeable on that subject. You're the expert.

- Prior to the interview, if possible, review your recorded performances to identify strengths and weaknesses.

- Be sure the TV station has your proper name, title and organization affiliation. Seeing either item appear incorrectly on the TV screen can throw you off guard.

- Try to convince yourself you're having a normal everyday conversation with someone.

- Prepare your voice before the interview. Many people are self-conscious about the way they sound. One way to lessen this fear is by relaxing your throat with a glass of lemon and hot water before leaving your house. Also, certain foods and beverages coat your throat, causing difficulty in swallowing and speaking. Before the interview, stay away from such things as cola drinks, chocolates and milk and milk products. It takes several hours to "uncoat" your throat from these products.

\section{Try this yourself...}

Analyze your mock news interview recording for "nervousness." Do you appear to feel comfortable in front of a camera? Do you look nervous? Do you look"natural"?

\section{Final Help}

By following the following "Be Attitudes," you should be successful in any interview setting.

Be prepared. Prepare in advance two or three key ideas you wish to get across. Anticipate key issues that will come up during the interview and be prepared to use those issues to launch your objectives. Think of questions you would ask.

Be positive. Turn negative questions or statements into positive responses. End every answer on a positive, upbeat note.

Be honest. Always tell the truth. If you don't and try to bluff, it will show. Your credibility is crucial. You want them to keep coming back to you as a reputable source.

Be brief. Crystallize your ideas into a few short phrases that summarize what you're trying to communicate.

Be yourself. Keep your voice at an even pace. Act naturally. Avoid technical language (jargon) or "big" words. It does not impress anyone.

Be comfortable, confident and take charge. Relax. You know more about the story topic than the interviewer. If not, you wouldn't be interviewed.

Be energetic. Be animated. Use gestures, facial expressions and body language to add vitality to your words. (Just don't overdo it.)

Be focused. Put your full attention on the interviewer. Look directly at the person asking the questions. Don't be concerned with distractions. 